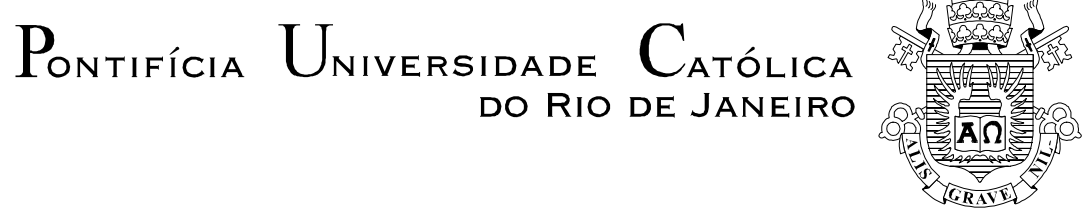

Marcos Antonio Bezerra Brito

\begin{abstract}
Uma Metódica do Sistema Tributário Nacional o Procedimento Fiscal Fazendário Federal no Constitucionalismo Contemporâneo
\end{abstract}

Tese de Doutorado

Tese apresentada como requisito parcial para a obtenção do grau de Doutor pelo Programa de Pós-Graduação em Direito do Departamento de Direito da PUC-Rio.

Orientador: Prof. José Ribas Vieira

Volume I

Rio de Janeiro

Setembro de 2010 
Pontifícia Universidade Católica $_{\text {do Rio de Janeiro }}$

Marcos Antonio Bezerra Brito

\section{Uma Metódica do Sistema Tributário Nacional \\ o Procedimento Fiscal Fazendário Federal no Constitucionalismo Contemporâneo}

Tese apresentada como requisito parcial para a obtenção do grau de Doutor pelo Programa de PósGraduação em Direito do Departamento de Direito da PUC-Rio, para avaliação da seguinte banca examinadora:

Prof. José Ribas Vieira

Orientador

Departamento de Direito - PUC-Rio

Profa . Ana Lúcia de Lyra Tavares Departamento de Direito - PUC-Rio

Prof. Fabio de Carvalho Leite Departamento de Direito - PUC-Rio

Prof. Adilson Rodrigues Pires

UERJ

Prof. Marco Aurélio Grecco

FGV-SP

Profa. Mônica Herz

Vice-Decana de Pós-Graduação do Centro de

Ciências Sociais - PUC-Rio

Rio de Janeiro, 13 de setembro de 2010 
Todos os direitos reservados. É proibida a reprodução total ou parcial do trabalho sem autorização da universidade, do autor e do orientador.

\section{Marcos Antonio Bezerra Brito}

Graduado em Administração (1991) e Direito (2002) pela Universidade Federal Fluminense, cursou aperfeiçoamento em Política e Estratégia pela Escola Superior de Guerra do Ministério da Defesa (2004), mestrado em Teoria do Estado e Direito Constitucional Tributário (PUC-Rio/2005), e doutorado em Direito Tributário na PUC-Rio, 2010. Pesquisador convidado na Deutsche Hochschule für Verwaltungswissenschaft - Speyer (Escola Alemã de Altos Estudos em Ciência da Administração de Speyer) em 2009, professor e Auditor Fiscal da Receita Federal do Brasil. Pósdoutorando em Administração Fazendária em Sistemas Multiníveis 2011-2012.

Ficha catalográfica

BRITO, Marcos Antonio Bezerra

Uma Metódica do Sistema Tributário Nacional: O Procedimento Fiscal Fazendário Federal no Constitucionalismo Contemporâneo; orientador: José Ribas Vieira. - Rio de Janeiro: PUC; Departamento de Direito, 2010.

2 vols. $30 \mathrm{~cm}$.

1. Tese (doutorado) - Pontifícia Universidade Católica do Rio de Janeiro, Departamento de Direito

Inclui referências bibliográficas.

1.Direito - Tese. 2. Constituição 3. seguridade social. 4. sistema tributário. 5. potestade publica. 6. legitimidade procedimental. 7. normatividade. 8. concretização. 9. metódica jurídica. 10. procedimento fiscal fazendário no constitucionalismo contemporâneo. I. Brito, Marco Antonio Bezerra. II. Vieira, José Ribas. III. Pontifícia Universidade Católica do Rio de Janeiro. Departamento de Direito. IV. Título. 


\section{Agradecimentos}

Ao Estado Brasileiro e à Igreja Católica,

Pela educação, o civismo, e por esta oportunidade. 


\section{Dedicatória}

A meus pais,

da infância, em casa,

da juventude, nas escolas

e desse início de maturidade na academia. 


\section{Resumo}

Brito, Marco Antonio Bezerra; Vieira, José Ribas. Uma metódica do sistema tributário nacional: o procedimento fiscal fazendário federal no constitucionalismo contemporâneo. Rio de Janeiro, 2010, 330p. Tese de Doutorado - Departamento de Direito, Pontifícia Universidade Católica do Rio de Janeiro.

A finalidade desta tese sobre o poder de polícia fiscal fazendário é propor um método de trabalho para a administração fazendária federal que atenda aos requisitos de legitimidade de suas decisões nos procedimentos fiscais, à vista das novas tarefas do estado constitucional contemporâneo brasileiro, fixadas pela CF88 no modelo de tributação estatal, o qual alterou o sistema de lançamento tributário federal.

\section{Palavras-chave}

Constituição; seguridade social; sistema tributário; potestade publica; legitimidade procedimental; normatividade; concretização; metódica jurídica; procedimento fiscal fazendário no constitucionalismo contemporâneo. 


\section{Abstract}

Brito, Marco Antonio Bezerra; Vieira, José Ribas (advisor). A methodic for the national taxation system: the federal fiscal taxation proceeding in the contemporary constitutionalism. Rio de Janeiro, 2010, 330p. PhD Thesis - Departamento de Direito, Pontifícia Universidade Católica do Rio de Janeiro.

This thesis about fiscal taxation proceedings has the purpose to offer a work methodic for the brazilian federal tax administration, to attend legitimation requirements for taxation proceedings and the new state tasks fixed for the taxation in the brazilian constitution, that has changed the federal taxation system.

\section{Keywords}

Constitution; social security; taxation system; potestade publica; procedural legitimation; normativity; concretization; juridical methodic; fiscal taxation proceeding. 


\section{Sumário}

Introdução posição do problema, nossa hipótese, justificativa, quadro de referências teóricas, metodologia e ordenação do tema

1. Teoria constitucional moderna ou contemporânea? A nova constitucionalização da segurança e da seguridade social

1.1. Introdução - Constituição e teoria constitucional contemporânea da segurança social como seguridade

1.2. Constituição e Teoria Constitucional Contemporânea: novo quadro teórico constitucional nos anos 90 do século XX

1.2.1. Uma teoria da constituição com garantia dos direitos fundamentais como eixo central ante a fragmentação da soberania estatal: necessidade política e defesa da constituição

1.2.2. O marco teórico clássico da teoria constitucional: governo de crise e "ditadura constitucional"

1.2.3. Segurança e liberdade na sociedade de risco global 41

1.2.4. Sociedade de risco e a disciplinarização da segurança

1.2.5. Segurança, diversidade e solidariedade em lugar de liberdade, igualdade e fraternidade

2. Elementos de teoria da justiça e de teoria do estado nas decisões políticas e jurídicas: o procedimento de legitimação das decisões do estado autoridade do interesse público ao estado administração dos recursos sociais

2.1. Uma introdução genealógica da potestade publica fazendária: a coexistência dos indivíduos e do Estado

2.2. Pontos básicos

2.3. A desconstrução da força do direito fundada na mística da autoridade

2.3.1. A tematização desconstrutivista de direito e justiça através da investigação fenomenológica de três aporias, a necessidade de justiça constitucional e a possibilidade de justiça estatal no exercício da potestade publica fiscal fazendária

2.4. Pela estrada anti-formalista da atuação estatal contemporânea do após-guerra: neopragmatismo e controle das tarefas constitucionais do estado-administração

2.4.1. Significado e intenção nas tarefas constitucionais do estado 
do estado-administração cria o direito no cumprimento de suas tarefas constitucionais

2.4.3. A legitimação do exercício do poder-dever estatal pelo cumprimento de suas tarefas fixadas na constituição e na legislação tributária

2.4.4. A vontade e o poder no juízo jurídico estatal contemporâneo

2.5. A desconstrução da máscara do direito vestido de justiça: do círculo hermenêutico de auto-justificação do direito como justiça à constitucionalização do direito na situação hermenêutica aberta para dentro do tempo dos procedimentos de exercício da potestade publica fazendária

2.5.1. Cotejo desconstrutivista do estado autoridade do interesse público ao estado administração dos recursos sociais

3. Elementos de teoria da tributação e de teoria do estado no câmbio de papéis do estado moderno ao estado constitucional contemporâneo no Brasil: A função fiscal extrativa de tributos da coerção e resistência à tributação estatal para a tributação de solidariedade social

3.1. Coerção e capital: o motor das trajetórias de formação do estado moderno

3.2. Capital, cidades, estado e coerção: mirada na experiência brasileira

3.3. Coerção, estados e dominação

3.4. Coerção e capital da Europa para a formação do aparelho extrativo de tributos no Brasil

3.5. A apreensão, a fabricação ou a compra da coerção e seu controle pelo estado. A opção do Estado Brasileiro pela disciplina sistemática da extração de tributos segundo sua função fiscal

3.6. O estado moderno e o pagamento das dívidas

3.7. O pagamento das dívidas sociais, o custeio da promoção social e a tributação no estado constitucional contemporâneo do após-guerra: $\mathrm{O}$ modelo contemporâneo de tributação no Brasil para o custeio da seguridade social no procedimento fiscal fazendário federal

4. Os direitos fundamentais no procedimento fiscal fazendário e no processo administrativo / judicial tributário: a atuação da liberdade originária e da liberdade comunitária - Estudo em teoria constitucional contemporânea dos direitos fundamentais para compreensão, análise e projeção nas decisões formadoras do sistema tributário brasileiro diferenciado pelas fixações da CF88

4.1. Questões motivadoras deste estudo e resposta introdutória

4.2. Estudo em teoria constitucional contemporânea dos direitos fundamentais para compreensão, análise e projeção nas decisões 
formadoras do sistema tributário brasileiro diferenciado pelas fixações da CF88

4.2.1. Introdução

4.2.2. Categorias de estudo para compreensão, análise e projeção nas decisões do procedimento fiscal fazendário e do processo administrativo / judicial tributário

4.2.2.1. Os direitos fundamentais na "teoria interna", na "teoria externa", no "princípio da ponderação" e na "ponderação de bens" ou "modelo dos direitos fundamentais enquanto princípios"

4.2.2.1.1. Os direitos fundamentais na "teoria interna" e na "teoria externa" pela noção de liberdade comunitária.

4.2.2.1.2 Os direitos fundamentais na "teoria interna" e na "teoria externa", pela noção de liberdade originária:

4.2.2.1.3 Os direitos fundamentais na "teoria interna", na "teoria externa", e as liberdades originária e comunitária

4.2.2.2. Direitos fundamentais e "ponderação": "princípio da ponderação", ponderação de princípios" e "ponderação de bens"

4.2.2.2.1 A ponderação pela noção de liberdade comunitária 123

4.2.2.2.2. A ponderação pela noção de liberdade originária

4.2.2.3. A hierarquia das normas constitucionais: o sentido dos direitos fundamentais e sua significação constitutiva do sistema jurídicoconstitucional de valores nas normas constitucionais, nas leis gerais e na legislação em geral

4.2.2.4. Direitos fundamentais absolutos e / ou relativos

4.2.2.5. Restrições ao legislador previstas / não previstas nas constituições

4.2.2.6. Reservas ao legislador (geral, diferenciada e simples) e limites

4.2.2.7. Mecanismos formais / materiais de controle da conformação / restrição de direitos fundamentais: ponderação, razoabilidade e proporcionalidade

5. As transformações no sistema tributário brasileiro contemporâneo e no sistema de lançamento tributário federal

5.1. Introdução: $O$ direito tributário brasileiro como sistema e como norma de decisão

5.2. Sistemas, sistemas jurídicos, e sistema tributário nacional: a tributação como prática de ciência e como ciência prática

5.2.1. Direito, sistema e interpretação constitucional tributária pelo STF

5.3. O problema da legitimação das valorações no direito e da construção do sistema constitucional tributário jurídico / normativo 
5.3.1. Sobre o intento de práxis metódica da jurisprudência constitucional tributária do STF

5.4. O problema da densidade valorativa dos princípios constitucionais expressos

5.5. Meios de legitimação da atuação do estado em sua função fiscal: procedimento sistêmico e procedimento ético-discursivo

5.5.1. A legitimação das valorações no direito pelo procedimento sistêmico luhmanniano

5.5.2. A Legitimação das valorações em direito pelo procedimento éticodiscursivo

5.6. O trabalho de concretização do direito segundo o sistema tributário federal brasileiro

5.6.1. O sistema tributário brasileiro e suas diferenciações expressas na constituição e na legislação

5.6.2. O trabalho da metódica estruturante do direito segundo as diferenciações do sistema tributário federal brasileiro

5.6.3. O trabalho metódico de concretização do direito segundo as diferenciações expressas no sistema de lançamento tributário federal

5.6.4. O itinerário dos juízos jurídico-tributários do cidadão e do decididor estatal

6. Elementos dogmáticos, teóricos e metódicos de decisão nos procedimentos de lançamento tributário da administração fazendária federal - Receita Federal do Brasil

6.1. Introdução

6.2. Elementos dogmáticos de decisão na constituição de obrigações e créditos

6.3. O Procedimento Administrativo Fiscal da Receita Federal do Brasil

6.4. O direito tributário e os princípios político-jurídicos

6.5. O Registro de Procedimento Fiscal

6.6. O poder-dever da Administração Fazendária no Brasil

6.7. A prestação de informações e a movimentação financeira

6.8. A Requisição de Informações Sobre a Movimentação Financeira $\mathrm{RMF}$

6.9. Elementos dogmáticos, teóricos e metódicos da potestade publica no procedimento administrativo fiscal federal

7. O procedimento fiscal e o exercício do poder de polícia fazendário no sistema tributário federal do Brasil e da Alemanha: um ensaio metódico comparativo do conjunto, do sistema e da estrutura das normas 
7.2. As especificidades do procedimento fiscal fazendário no âmbito do exercício do poder de polícia administrativo

7.2.1. Uma genealogia do poder de polícia: a co-existência dos indivíduos e do Estado

7.2.2. O poder de polícia fazendário estatal

7.3. Construção da escolha metódica de abordagem comparativa do procedimento fiscal fazendário brasileiro e alemão, a partir dos modelos lógicos "conjunto", "sistema" e "estrutura"

7.3.1. Noções de conjunto, sistema e estrutura, a cidadania e a função fiscal, e o sistema constitucional tributário legislado

7.3.2. O sistema tributário nacional expresso na constituição e na legislação, segundo elementos de teoria de conjuntos, elementos de teoria de sistemas e elementos de teoria de estruturas

7.4. Exame tópico de um conjunto comparativo dos textos de normas / normas constitucionais de exercício do poder de polícia da administração fazendária da atual Constituição do Brasil e da Lei Fundamental Alemã: intersecções e especificidades distintivas de cada conjunto

7.5. Sobre o poder de polícia fazendário nos sistemas jurídicos infraconstitucionais contemporâneos do Brasil e da Alemanha

7.5.1. Um cotejo comparativo do poder de polícia fazendário nos sistemas infraconstitucionais do Brasil e da Alemanha

7.6. Identificação tópica de referências para o exercício do poder de polícia fazendário no procedimento fiscal federal pelo exame das estruturas normativas dos sistemas tributários do Brasil e da Alemanha

7.6.1. Os elementos dogmáticos e metódicos de concretização jurídicotributária no procedimento fiscal fazendário do Brasil e da Alemanha

8. Conclusões

9. Referências Bibliográficas 


\section{Lista de Figuras}

Elementos de método estruturantes da decisão jurídica no procedimento fiscal do Brasil e da Alemanha - Atividade: fiscalização (capítulo 7) Primeiro grupo

Elementos de método estruturantes da decisão jurídica no procedimento fiscal do Brasil e da Alemanha - Atividade: fiscalização - Segundo grupo 